\title{
A systematic review and meta-analysis of data on pregnant women with confirmed COVID-19: Clinical presentation, and pregnancy and perinatal outcomes based on COVID-19 severity
}

\author{
Zohra S Lassi ${ }^{1,2}$, Ali Ana ${ }^{1,2}$, \\ Jai K Das ${ }^{3}$, Rehana A Salam ${ }^{3}$, \\ Zahra A Padhani ${ }^{3}$, Omer \\ Irfan $^{4}$, Zulfiqar A Bhutta ${ }^{4,5}$ \\ ${ }^{1}$ Robinson Research Institute, the \\ University of Adelaide, Adelaide, \\ Australia \\ ${ }^{2}$ Adelaide Medical School, the \\ University of Adelaide, Adelaide, \\ Australia \\ ${ }^{3}$ Division of Women and Child \\ Health, the Aga Khan University, \\ Karachi, Pakistan \\ ${ }^{4}$ Centre for Global Child Health, \\ the Hospital for Sick Children \\ (SickKids), Toronto, Canada \\ ${ }^{5}$ Centre of Excellence in Women \\ and Child Health, the Aga Khan \\ University, Karachi, Pakistan
}

\section{Correspondence to:}

Zulfiqar A Bhutta, PhD

Centre for Global Child Health

The Hospital for Sick Children (SickKids)

Toronto, Canada

zulfiqar.bhutta@sickkids.ca

Zohra S Lassi, PhD

Robinson Research Institute

Adelaide Medical School

The University of Adelaide

Adelaide

South Australia

Australia - 5005

Zohra.lassi@adelaide.edu.au
Background We determined the clinical presentation, risk factors, and pregnancy and perinatal outcomes in pregnant women with confirmed COVID-19 and identified if these are different based on COVID-19 severity.

Methods We included all observational studies on pregnant women with confirmed COVID-19 reporting clinical presentation, risk factors, and pregnancy and perinatal outcomes. We included all studies published between Dec/2019-Feb/2021 in Medline, Embase, the WHO COVID-19 databases, and clinicaltrials.gov. The methodological quality of cohort and case-series was assessed using NHLBI criteria.

Results 31016 pregnant women from 62 studies were included. Women were an average of 30.9 years of age, most $(77.7 \%)$ were in the third trimester, and $16.4 \%$ developed severe COVID-19. Nearly half were asymptomatic, while the most commonly reported symptoms were cough, fever, fatigue, and anosmia/ageusia. About $7 \%$ were admitted to the intensive care unit (ICU), $8 \%$ required mechanical ventilation, and $2 \%$ of the women died. Almost $80 \%$ of women delivered; $48.4 \%$ had cesarean births. Among newborns, $23.4 \%$ were preterm ( $<37$ weeks), $16.6 \%$ were low birth weight, and $23.7 \%$ were admitted to neonatal ICU. A total of 21 stillbirths (1.6\%) and 24 neonatal deaths (1.6\%) were recorded, while 50 babies (3.5\%) were COVID-19 positive. Studies comparing pregnant women with severe and non-severe COVID-19 showed that women with severe COVID-19 were 3.7 years older and the risk of severe COVID-19 was 1.5 times higher among women $>35$ years. The risk of severe COVID-19 was significantly higher among women who were obese, had smoked, diabetic, and had pre-eclampsia. The risk of preterm birth was almost 2.4 folds among women with severe COVID-19.

Conclusions Our review suggests a heightened risk of COVID-19 severity and adverse pregnancy and perinatal outcomes among women with certain demographic and health profiles. These findings can inform the formation of current guidelines; however, these should be constantly updated as the global COVID-19 scenario unfolds.

Registration PROSPERO: CRD42020182048.

Since its emergence in December 2019, the novel coronavirus-2 has fast become one of the greatest global health challenges of the last century. The virus has so far (as of June 21,2021 ) been spread to 216 countries and territories, infected around 178 million people, and resulted in 3.86 million deaths [1]. Because of the nature of spread, the number of cases has been exponentially increasing every day. Although the virus is prevalent in all ages regardless of gender, it is more severe and can cause deaths among 
those who have a pre-existing disease [2], and those who are disadvantaged and lack access and affordability to health services [3]. Majority of the deaths reported worldwide are among the elderly or those with co-morbidities and poor immunity [4]. Women during pregnancy often face several pregnancy-related complications and are more susceptible to respiratory pathogens that may place them at higher risk of adverse outcomes [5]. The new coronavirus is genetically closer to Severe Acute Respiratory Syndrome-Corona virus-1 (SARS$\mathrm{CoV}-1$ ), which in earlier studies have shown the high occurrence of adverse maternal and neonatal outcomes including preterm birth, intrauterine growth restriction (IUGR), endotracheal intubation, and intensive care unit (ICU) admission, with minimal chance of vertical transmission [6,7]. A recent systematic review on pregnancies infected with recent and past coronavirus-related illnesses (including SARS-CoV-1 and Middle East Respiratory Syndrome - MERS) has established a high risk of miscarriage, pre-eclampsia, preterm birth, and perinatal death [8]. However, they included very few cases of SARS-CoV-2 in their analysis (41 cases only) [8]. A more recently published review on confirmed and suspected pregnant women with COVID-19 reported that advanced maternal age, pre-existing comorbidities and increased body mass index (BMI) are the risk factors for severe COVID-19 [9].

After the emergence of COVID-19, many evidence syntheses have been published, however, the majority of those have presented limited data from case reports and case series only which lacked methodological robustness [10-13]. We found few systematic reviews with a larger population of pregnant women $[9,14]$. Of these reviews, one has presented the clinical and laboratory features of more than 2500 pregnant women and reported increased maternal ICU admissions among women in higher age brackets and those with comorbidities [14]. Another recent systematic review of 77 studies included women of reproductive age (both confirmed and suspected cases) and reported outcomes on pregnant and non-pregnant women [9]. Although systematic reviews on the topic exist, but with a rapid rate of accumulating evidence from larger prospective studies, it is important to frequently update the evidence to better understand the clinical presentation, risk factors, and pregnancy and perinatal outcomes in pregnant women with laboratory-confirmed COVID-19 irrespective of clinical signs and symptoms and severity of COVID-19, and at the same time, identify women at a higher risk for COVID-19 severity and its impact on pregnancy, birth, and perinatal outcomes.

\section{METHODS}

\section{Eligibility criteria, study selection, information sources, search strategy}

The protocol of the review has been registered with PROSPERO - CRD42020182048. A systematic review was carried out using Preferred Reporting Items for Systematic Review and Meta-analysis (PRISMA) guidelines to assess the impact of COVID-19 on pregnancy, birth, and perinatal outcomes [15]. This systematic review included large cohort and case series including multi-country and multi-center studies, describing the clinical presentation, risk factors, and pregnancy and perinatal outcomes in pregnant/postpartum women with laboratory-confirmed COVID-19 (serology or RT-PCR) irrespective of clinical signs and symptoms and severity of COVID-19 [16].

The search strategy was prepared using the MeSH and free text terms for "coronavirus" and "pregnant women" (Table S1 in the Online Supplementary Document) and applied to databases including Medline, EMBASE, the World Health Organization (WHO) COVID-19 global literature on coronavirus disease, China Knowledge Resource Integrated Database (CNKI), and Google Scholar. Pre-print databases MedRxiv (https://www. medrxiv.org), and BioRxiv (https://www.biorxiv.org, and ongoing registered studies on Clinicaltrials.gov were also searched. We also contacted established groups that were conducting and compiling surveillance data from large cohorts. The bibliographies of all included studies and existing systematic reviews were also handsearched. No language restriction was applied and the review included all eligible studies published since December 2019. The last search date was Feb 15, 2021. The review excluded studies on non-pregnant women, infants (beyond neonatal age), children, and other adult populations presenting to hospitals with COVID-19 like symptoms. The review also excluded systematic and narrative reviews, guidance/guidelines, opinion papers, and commentaries with no mention of original cases. We excluded case reports identified in the searches (Table S2 in the Online Supplementary Document), also the studies that only reported universal screening and positive cases without any mention of clinical presentation, risk factors, and pregnancy and perinatal outcomes. For studies with overlapping cases, we contacted the authors to confirm the center name and time period in which the participants were included and judged the overlaps with other studies. When we couldn't hear from study authors we only included the study with a larger sample size when the hospital/medical centers and the time period in which cases were included were similar, and when it wasn't very clear we did not include the study (Table S3 in the Online Supplementary Document). When there was uncertainty, the corresponding author of the primary study was contacted to confirm the information. 


\section{Data extraction and quality assessment}

All identified studies were uploaded into Covidence Systematic Review Software for screening [17] and then independently sifted for relevance by two review authors (ZSL and AA) and discrepancies were resolved by discussion. Data were independently extracted from eligible studies by two authors (ZSL and AA) using the pre-designed extraction sheet. Information was extracted on publication year; location; study design; sample size; clinical presentation of COVID-19 like symptoms; past medical history (comorbidities); COVID-19 diagnosis, severity and management; pregnancy, birth, and perinatal outcomes; and neonatal COVID-19 status. The methodological quality of included studies was assessed using criteria outlined by the National Heart, Lung, and Blood Institute (NHLBI) [18].

\section{Data synthesis}

The pooled analysis was performed using the Comprehensive Meta-Analysis (CMA) Software [19] and Joanna Briggs Institute (JBI) SUMARI software [20]. The meta-analysis pooled overall prevalence using Dersimonian and Laird random-effect meta-analysis after transforming data using Freeman-Tukey transformation arcsine square root transformation. The review pooled overall means and proportion for clinical manifestations, risk factors, pregnancy, and perinatal outcomes and reported their 95\% confidence intervals (CI) and the percentage of variation across studies that is due to heterogeneity rather than chance using $\mathrm{I}^{2}$ statistics.

The review assessed the impact of COVID-19 severity on pregnancy, birth, and perinatal outcomes from non-comparative dichotomous data using bivariate analysis [21]. Since severity was defined differently in the included studies, therefore, for this review, we categorized COVID-19 case severity based on the WHO definition as [22]:

- Non-severe (asymptomatic/mild, and moderate cases): women with no symptoms, mild symptoms (case definition for COVID-19 without evidence of viral pneumonia or hypoxemia), and moderate symptoms (clinical signs of pneumonia with no hypoxemia on room air).

- Severe (severe and critical cases): women with dyspnoea with a respiratory rate of $\geq 30$ breaths per minute and hypoxemia on room air, requiring oxygen therapy or mechanical (invasive or non-invasive) ventilation including extracorporeal membrane oxygenation (ECMO).

Studies that compared pregnant women with non-severe and severe COVID-19 and reported outcomes were separately pooled. The random-effects models were prepared using Review Manager 5.4 (The Nordic Cochrane Centre, The Cochrane Collaboration, Copenhagen, Denmark) [23] and the outcomes were summarized as risk ratios (RR) and mean difference (MD) with 95\% CIs.

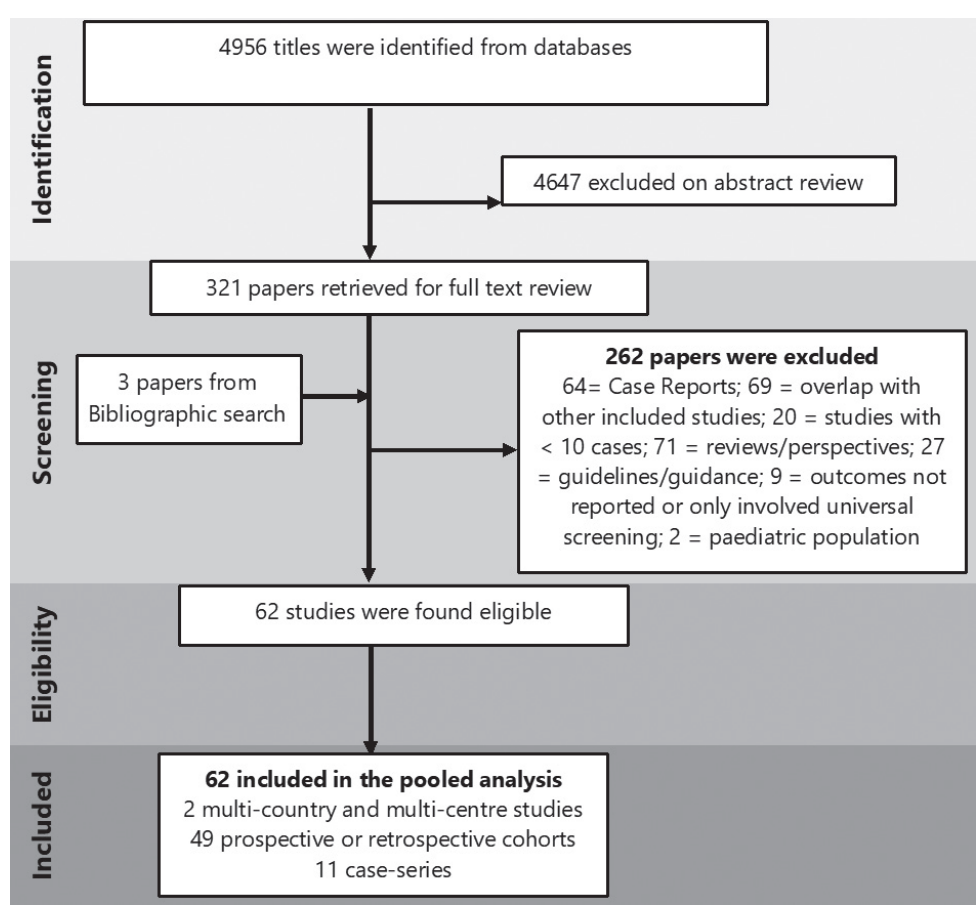

Figure 1. PRISMA flow diagram of study selection process.

\section{RESULTS \\ Study selection}

A total of 4956 studies were identified using the search strategy, after removing the duplicates. Full texts of 321 papers were reviewed and finally, 62 studies (including 31016 pregnant women) met the eligibility criteria (Figure 1).

\section{Characteristics of included studies}

Of the 62 included studies, 11 were case-series, and 51 were prospective/retrospective cohorts including two multi-country studies. Of all the studies, one paper was published in Chinese [24]. Characteristics of studies included are summarized in Table S4 in the Online Supplementary Document. We identified a study that has reported only on the clinical presentation of 23434 pregnant women from the USA without mention of birth and pregnancy outcomes. Since this large USA study did overlap with other studies from the USA (included in this systematic review), we only considered this large study for calculating 


\section{Pregnant women with COVID-19}
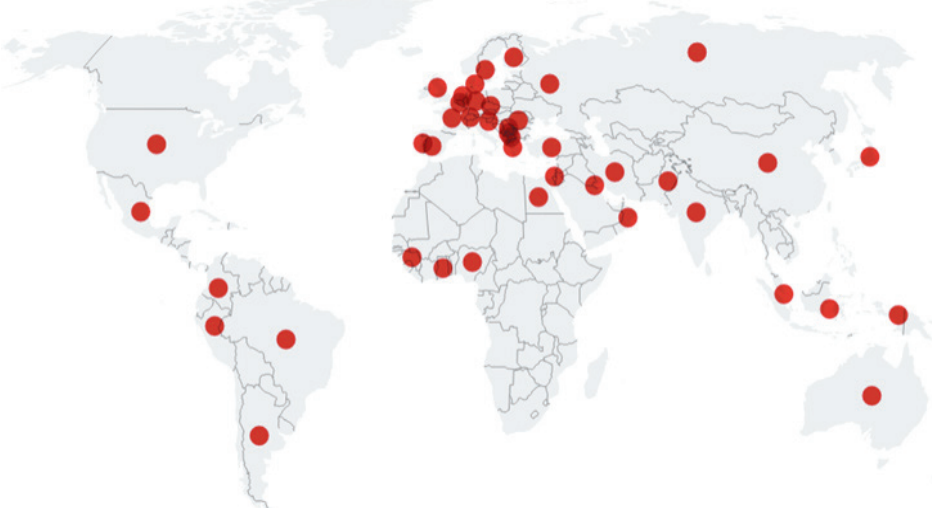

Source: Lassi et al. 2020 • Created with Datawrapper

Figure 2. Distribution of included studies on global map.

the pooled prevalence of the clinical presentation in pregnant women. However, for birth and perinatal outcomes, other studies from the USA were considered for pooled prevalence calculation.

Studies included were from 44 countries of the six continents: Australia, Africa (Egypt, French Guinea, Ghana, Nigeria), Asia (China, India, Indonesia, Iran, Japan, Kuwait, Oman, Pakistan, Russia, Singapore), Europe (Belgium, Czech Republic, Denmark, Finland, France, Germany, Greece, Israel, Italy, Moscow, North Macedonia, Portugal, Republic of Kosovo, Romania, Serbia, Slovenia, Spain, Sweden, Switzerland, the Netherlands, Turkey, the UK), North America (Dominica Republic, Mexico, the USA), and South America (Argentina, Brazil, Colombia, Peru) (Figure 2).

Of the 31016 pregnant women with COVID-19, information on severity was reported for 8.8\% ( $\mathrm{n}=2743 ; 13$ studies) of the included women. Of these, $85.6 \%$ had non-severe COVID-19, and the remaining 14.4\% had severe COVID-19. We performed a separate pooled analysis of 13 studies that compared pregnant women with non-severe and severe COVID-19 in the same study [24-39].

\section{The methodological quality of included studies}

The methodological quality of included studies is assessed and reported in Tables S5a and S5b in the Online Supplementary Document. Almost 80\% of the studies reported the research objective and population, however eligibility, blinding of assessment, and loss to follow-up were not clearly stated in the studies. Of all the case-series, the majority failed to report the statistical methods, however, the rest of the domains were reported in those studies.

\section{Synthesis of the results}

Sociodemographic and basic health profile of all included women: Table 1 presents the socio-demographic and basic health profile of pregnant women infected with COVID-19. The mean age of pregnant women presenting

Table 1. Socio-demographic and health profile of pregnant women with COVID-19 - all cases

\begin{tabular}{|c|c|c|c|c|c|}
\hline \multirow{2}{*}{ VARIABLES } & & \multicolumn{4}{|c|}{ ALL CASES $(\mathrm{N}=31016)$} \\
\hline & & \# studies & $\begin{array}{l}\text { Total } \\
\text { events/participants }\end{array}$ & $\begin{array}{l}\text { Pooled proportion } \\
(\%)\end{array}$ & $\begin{array}{l}\text { Heterogeneity } \\
\qquad\left(I^{2 \%}\right)\end{array}$ \\
\hline \multirow{3}{*}{ Age (years) } & Mean age (years) & 40 & & $30.92 \pm 0.65$ & 99.7 \\
\hline & $<35$ years & 12 & $20476 / 25256$ & 54.9 (38.6 to 70.7$)$ & 99.0 \\
\hline & $\geq 35$ yearsa & 10 & $4546 / 24883$ & $31.3(23.5$ to 39.6$)$ & 95.0 \\
\hline \multirow{6}{*}{$\begin{array}{l}\text { Gestational } \\
\text { age (Weeks) }\end{array}$} & Mean gestational age & 22 & & $33.36 \pm 0.71$ & 99.6 \\
\hline & First trimester & 9 & $184 / 1847$ & $13.9(6.4$ to 23.3$)$ & 94.5 \\
\hline & Second trimester & 11 & $369 / 1887$ & 20.7 (13.2 to 29.2$)$ & 90.6 \\
\hline & Third trimester & 15 & $1373 / 2184$ & 77.7 (63.4 to 89.5) & 97.5 \\
\hline & $\geq 37$ weeks & 4 & $360 / 1120$ & $39.3(9.3$ to 74.5$)$ & 99.0 \\
\hline & $<37$ weeks & 3 & $602 / 1056$ & $65.1(22.9$ to 96.9$)$ & 99.3 \\
\hline \multirow{2}{*}{ Parity } & Nulliparous & 18 & $667 / 1821$ & $34.7(28.4$ to 41.3$)$ & 87.4 \\
\hline & Multiparous & 9 & $464 / 887$ & $51.6(36.8$ to 66.2$)$ & 94.7 \\
\hline \multirow{6}{*}{ Ethnicity } & White & 8 & $5919 / 24962$ & $35.2(16.9$ to 55.9$)$ & 99.3 \\
\hline & Black & 6 & $3586 / 25199$ & $15.8(7.4$ to 26.5$)$ & 98.5 \\
\hline & Asian & 6 & $1246 / 24987$ & $61.8(19.3$ to 95.8$)$ & 99.9 \\
\hline & Central/Latin American & 4 & $7230 / 23760$ & $58.5(28.1$ to 85.7$)$ & 98.8 \\
\hline & Mixed & 2 & $62 / 488$ & $10.6(8.0$ to 13.6$)$ & 98.4 \\
\hline & Others & 4 & $972 / 24706$ & $2.1(0.4$ to 5.0$)$ & 93.8 \\
\hline \multirow{2}{*}{$\begin{array}{l}\text { Health } \\
\text { insurance }\end{array}$} & Private & 4 & $196 / 436$ & 49.4 (39.0 to 59.9) & 75.1 \\
\hline & Public & 4 & $265 / 476$ & $53.4(44.2$ to 62.5$)$ & 71.9 \\
\hline \multirow{4}{*}{$\begin{array}{l}\text { Body Mass } \\
\text { Index }\end{array}$} & Mean BMI & 16 & & $27.77 \pm 0.72$ & 99.0 \\
\hline & $<25$ & 2 & $130 / 435$ & $28.7(24.2$ to 33.3$)$ & 32.4 \\
\hline & 25 to $<30$ & 3 & $480 / 1166$ & $38.2(28.6$ to 48.3$)$ & 89.2 \\
\hline & $\geq 30$ & 13 & $735 / 26170$ & $19.3(10.5$ to 30.0$)$ & 98.8 \\
\hline
\end{tabular}




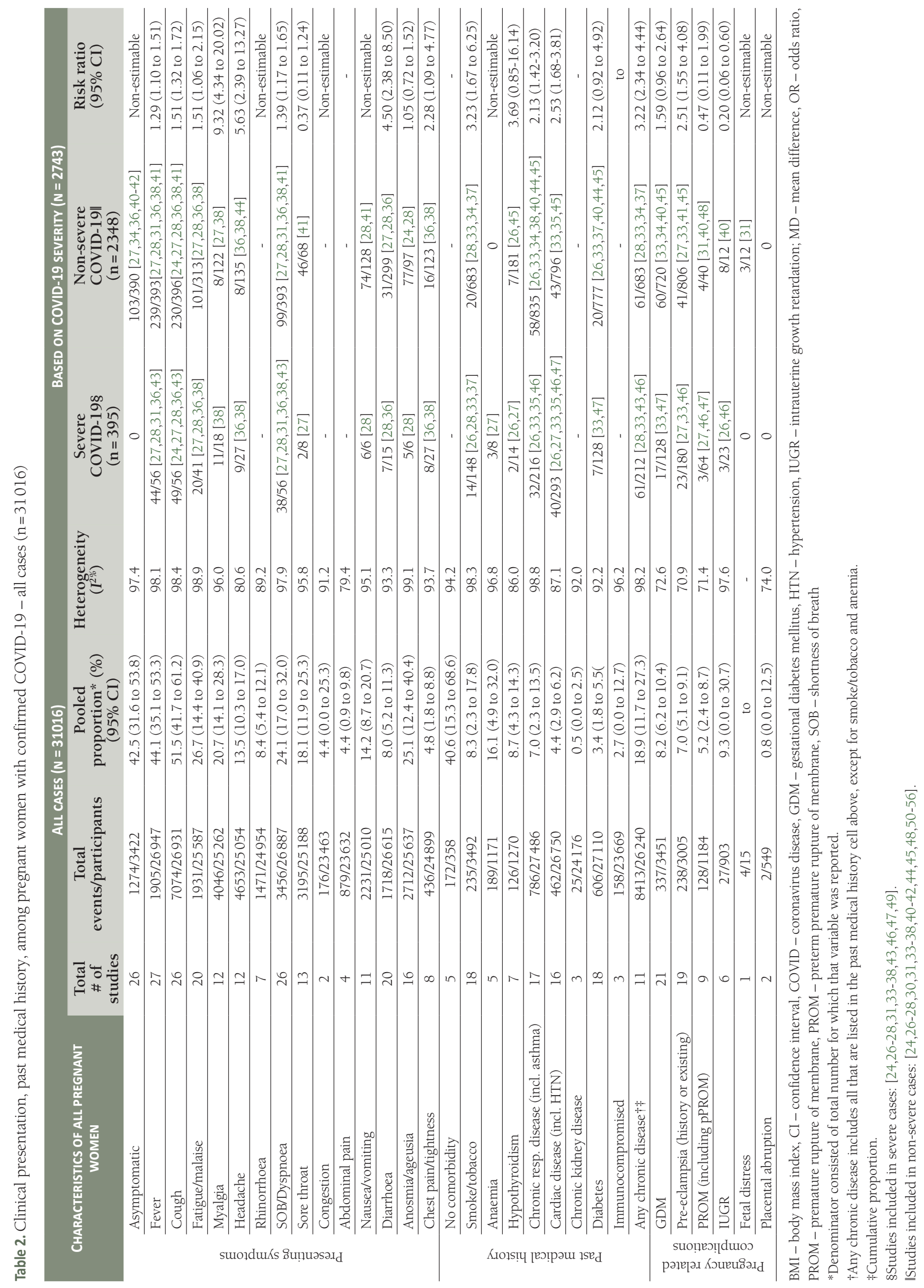


to the hospital was 30.92 years; of these, nearly one-third (31.3\%) were older than 35 years. Their mean gestational age on presentation was 33.36 weeks, with the majority $(77.7 \%)$ in the third trimester at the time of reporting. Half of all women were multiparous (51.6\%), and one-third were nulliparous (34.7\%). The majority of the women were Asian (61.8\%), followed by Central/Latin American (58.5\%), White (35.2\%), and Black (15.8\%). More than half of all women had public/state health insurance $(53.4 \%)$ and the other half had private health insurance (49.4\%). Their mean body mass index (BMI) was 27.77; of these 38.2\% were overweight and $19.3 \%$ were obese or morbidly obese.

Clinical presentation, comorbidities, and pregnancy complications: Table 2 presents the clinical manifestations, past medical history, and pregnancy-related complications among pregnant women with COVID-19. While almost half (42.5\%) of all women were asymptomatic, the most commonly reported symptoms were cough (51.5\%), fever $(44.1 \%)$, fatigue/malaise (26.7\%), and anosmia/ageusia (25.1\%). The other commonly reported symptoms included shortness of breath (SOB)/dyspnoea (24.1\%), myalgia (20.7\%), sore throat (18.1\%), and nausea/

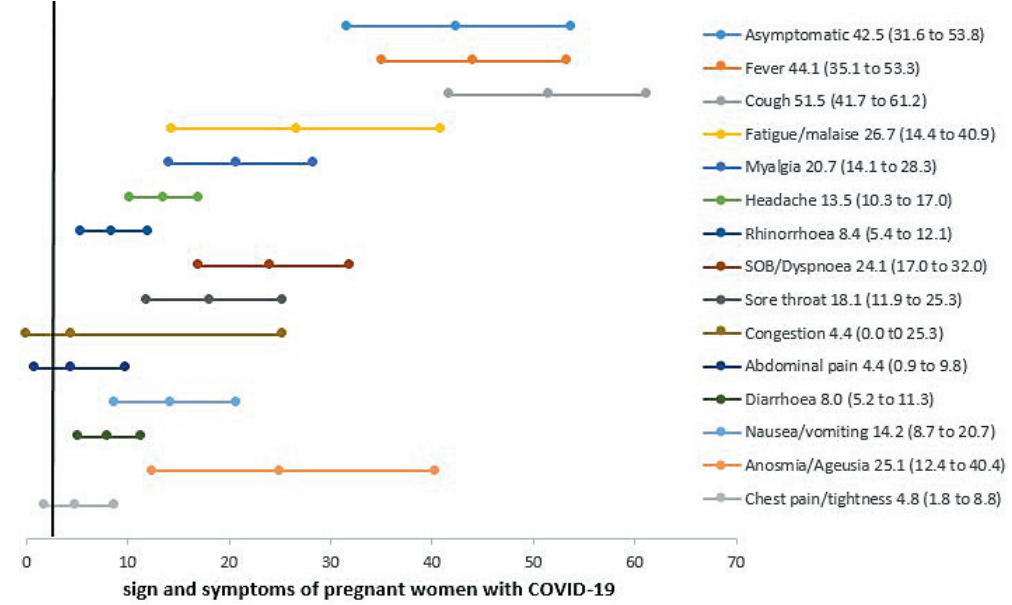

Figure 3. Clinical presentations on pregnant women with COVID-19. The figure presents pooled proportion with $95 \%$ confidence intervals using random-effect model. vomiting (14.2\%) (Figure 3). The risk of developing severe COVID-19 was higher among women who presented with fever, cough, fatigue/malaise, myalgia, headache, SOB/dyspnoea, diarrhea, and chest pain/tightness compared to non-severe cases. Table 2.

While almost half (40.6\%) had no past medical history, a small proportion of women had anemia (16.1\%), hypothyroidism (8.7\%), gestational diabetes mellitus (GDM) (8.2\%), and pre-eclampsia (7.0\%). The risk of having severe COVID-19 was higher among those who had smoked $(\mathrm{RR}=3.23$; $95 \% \mathrm{CI}=1.67$ to 6.25$)$, chronic cardiac diseases including hypertension $(\mathrm{RR}=2.53 ; 95 \% \mathrm{CI}=1.68$ to 3.81$)$, chronic respiratory diseases including asthma $(\mathrm{RR}=2.13 ; 95 \% \mathrm{CI}=1.42$ to 3.20$)$, and pre-eclampsia $(\mathrm{RR}=2.51 ; 95 \% \mathrm{CI}=1.55$ to 4.08$)$ Table 2.

Clinical and ICU management: Table 3 presents the management of COVID-19 and related complications. The majority of the women were managed with anticoagulants (50.6\%) (including heparin, enoxaparin), followed by antibiotics (45.8\%) (including azithromycin, vancomycin, ceftriaxone, piperacillin, moxifloxacin, levofloxacin, polymexicin, salbactam, impenam, abipenam, meropenam, sulphanilamide, omidazole, cefazolin, ceftazidime, other quinolone, cephalosporin, and macrolides), hydroxychloroquine (41.3\%), antivirals (33.4\%) (including oseltamivir, ganciclovir, lopinavir, peramivir, favipiravir, ritonavir, arbidole, ribavirin, interferon), immunotherapy (16.2\%), and corticosteroids (14.7\%) (including methylprednisolone, dexamethasone, betamethasone). Almost one-quarter were put on oxygen therapy (20.6\%).

Table 3. Management of COVID-19 and related complications - all cases ( $\mathrm{n}=31016)$

\begin{tabular}{|c|c|c|c|c|c|}
\hline \multicolumn{2}{|c|}{$\begin{array}{l}\text { CHARACTERISTICS OF ALL PREGNANT } \\
\text { WOMEN }\end{array}$} & $\begin{array}{l}\text { TOTAL \# OF } \\
\text { STUDIES }\end{array}$ & $\begin{array}{c}\text { TOTAL } \\
\text { EVENTS/PARTICIPANTS }\end{array}$ & $\begin{array}{l}\text { POOLED PROPORTION (\%) } \\
(95 \% \mathrm{Cl})\end{array}$ & $\begin{array}{l}\text { HETEROGENEITY } \\
\left(1^{2 \%}\right)\end{array}$ \\
\hline & Antibiotic & 14 & $448 / 1140$ & $45.8(27.0$ to 65.3$)$ & 97.5 \\
\hline & Antiviral & 17 & $514 / 1742$ & $33.4(16.3$ to 53.1$)$ & 98.4 \\
\hline & Hydroxychloroquine & 11 & $305 / 877$ & $41.3(21.0$ to 63.1$)$ & 97.2 \\
\hline & Anticoagulants & 5 & $282 / 1219$ & $50.6(12.8$ to 88.0$)$ & 99.4 \\
\hline & Corticosteroids & 8 & $73 / 425$ & $14.7(8.0$ to 22.8$)$ & 75.5 \\
\hline & Immunotherapy & 6 & $45 / 827$ & $16.2(1.7$ to 39.7$)$ & 96.6 \\
\hline & Plasma therapy & 4 & $183 / 385$ & 22.5 (0.0 to 79.3$)$ & 99.2 \\
\hline & Oxygen therapy & 20 & $321 / 1812$ & 20.6 (11.0 to 32.2) & 96.3 \\
\hline & ICU admission & 22 & $717 / 27865$ & $7.2(4.8$ to 9.9$)$ & 94.1 \\
\hline \multirow{5}{*}{$\begin{array}{l}\text { ICU } \\
\text { management }\end{array}$} & Mechanical ventilation & 20 & $282 / 4048$ & $7.7(3.7$ to 12.9$)$ & 95.8 \\
\hline & Non-invasive ventilation & 5 & $268 / 1463$ & $15.1(3.3$ to 32.4$)$ & 97.0 \\
\hline & ECMO & 6 & $31 / 24937$ & $0.3(0.0$ to 1.2$)$ & 79.8 \\
\hline & ARDS & 4 & $30 / 522$ & $10.0(0.1$ to 25.3$)$ & 91.6 \\
\hline & Maternal death & 14 & $208 / 27680$ & $2.0(0.8$ to 3.8$)$ & 94.6 \\
\hline
\end{tabular}

ARDS - acute respiratory distress syndrome, CI - confidence interval, COVID - coronavirus disease, ECMO - extracorporeal membrane oxygenation, ICU - intensive care unit, MODS - multiple organ dysfunction syndrome 


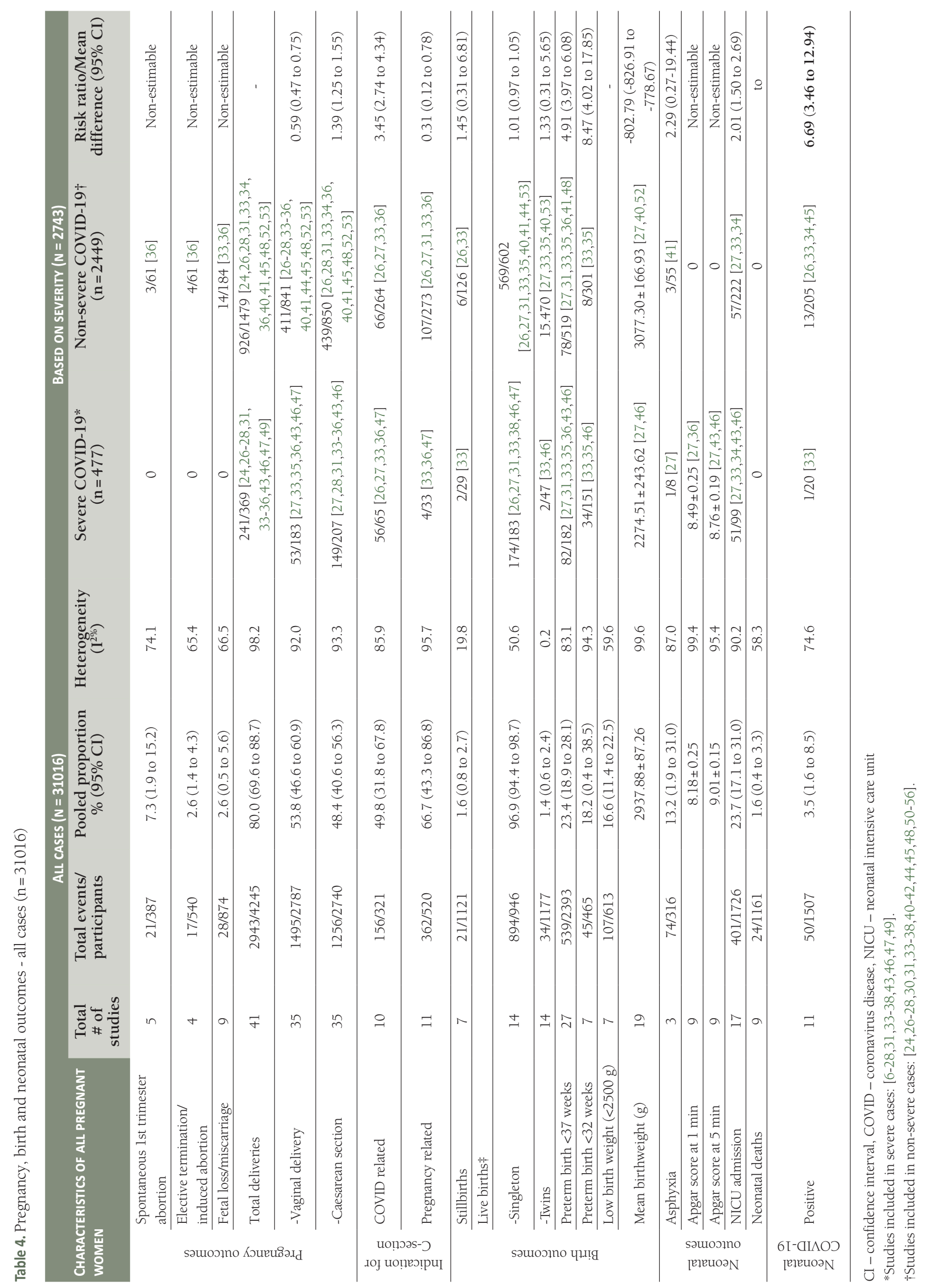


About $7.2 \%$ of the women were admitted to ICU; of which $7.7 \%$ required mechanical ventilation, while $15.1 \%$ required non-invasive ventilation (including BiPAP, CPAP) and 0.3\% required ECMO. Of all the pregnant women, 30 developed acute respiratory distress syndrome (ARDS) (10\%), and 208 (2.0\%) died (Table 3).

Pregnancy and perinatal outcomes: Table 4 presents pregnancy, birth, and perinatal outcomes. Some of the women experienced spontaneous first-trimester abortion (7.3\%), elective termination/induced abortion (2.6\%); and fetal loss/miscarriage (2.6\%).

Deliveries were reported for $80 \%$ of the included women. Of these, $53.8 \%$ of the women gave birth vaginally and $48.4 \%$ underwent cesarean section. The risk of cesarean birth was 1.39 times higher among severe cases. The majority (66.7\%) of cesarean births were performed because of pregnancy-related indications (60.9\%), and almost half (49.8\%) because of reasons related to COVID-19.

Table 5. Studies specifically comparing severe with non-severe COVID-19

\begin{tabular}{|c|c|c|c|c|c|c|}
\hline \multicolumn{2}{|c|}{ CHARACTERISTICS OF ALL PREGNANT WOMEN } & $\begin{array}{l}\text { TOTAL \# OF } \\
\text { STUDIES }\end{array}$ & $\begin{array}{c}\text { SEVERE } \\
\text { TOTAL EVENTS/ } \\
\text { PARTICIPANTS }\end{array}$ & $\begin{array}{l}\text { NON-SEVERE } \\
\text { TOTAL EVENTS/ } \\
\text { PARTICIPANTS }\end{array}$ & $\begin{array}{l}\text { ESTIMATE MD/RR } \\
(95 \% \mathrm{CI})\end{array}$ & $\begin{array}{c}\text { HETEROGENEITY } \\
\left(1^{2 \%}\right)\end{array}$ \\
\hline \multirow{12}{*}{ Demographic } & Mean age (years) & 6 & 50 & 310 & $3.72(2.26$ to 5.18$)$ & 60 \\
\hline & Age $<35$ years & 4 & $125 / 208$ & $526 / 745$ & $0.85(0.71$ to 1.01$)$ & 33 \\
\hline & Age $>35$ years & 4 & $73 / 208$ & $219 / 745$ & $1.49(1.21$ to 1.84$)$ & 2 \\
\hline & Mean gestational age (weeks) & 3 & 27 & 60 & $-2.36(-6.83$ to 2.11$)$ & 60 \\
\hline & Asian & 3 & $10 / 10$ & $135 / 135$ & $1.00(0.86$ to 1.17$)$ & 0 \\
\hline & Black & 1 & $29 / 75$ & $68 / 166$ & $0.94(0.67$ to 1.32$)$ & N/A \\
\hline & White & 2 & $14 / 83$ & $32 / 200$ & $1.17(0.43$ to 3.19$)$ & 64 \\
\hline & Hispanic & 3 & $34 / 101$ & $71 / 214$ & 1.18 (0.58 to 2.39$)$ & 77 \\
\hline & Others & 2 & $10 / 83$ & $26 / 200$ & $0.93(0.48$ to 1.83$)$ & 0 \\
\hline & Third trimester & 2 & $2 / 2$ & $27 / 27$ & $1.00(0.57$ to 1.77$)$ & 0 \\
\hline & Nulliparous & 3 & $9 / 21$ & $92 / 209$ & $0.93(0.55$ to 1.56$)$ & 0 \\
\hline & Multiparous & 3 & $9 / 21$ & $72 / 209$ & 1.07 (0.67 to 1.72$)$ & 0 \\
\hline \multirow{9}{*}{$\begin{array}{l}\text { Presenting } \\
\text { symptoms }\end{array}$} & Asymptomatic & 2 & $0 / 13$ & $28 / 187$ & $0.53(0.08$ to 3.65$)$ & 0 \\
\hline & Fever & 5 & $31 / 42$ & $193 / 325$ & $1.32(1.08$ to 1.61$)$ & 0 \\
\hline & Cough & 5 & $37 / 42$ & $184 / 328$ & $1.26(1.07$ to 1.48$)$ & 23 \\
\hline & Fatigue/malaise & 3 & $18 / 33$ & $86 / 205$ & 1.33 (0.75 to 2.34$)$ & 38 \\
\hline & Headache & 2 & $9 / 27$ & $7 / 123$ & 3.57 (1.28 to 9.94$)$ & 0 \\
\hline & SOB/Dyspnoea & 5 & $30 / 42$ & $55 / 325$ & 2.42 (1.76 to 3.34$)$ & 15 \\
\hline & Diarrhoea & 2 & $7 / 15$ & $29 / 191$ & 3.07 (1.92 to 4.92$)$ & 0 \\
\hline & Anosmia/Ageusia & 2 & $6 / 7$ & $77 / 97$ & $1.08(0.77$ to 1.53$)$ & 0 \\
\hline & Chest pain/tightness & 2 & $8 / 27$ & $18 / 123$ & $1.96(0.34$ to 11.35$)$ & 79 \\
\hline \multirow{6}{*}{$\begin{array}{l}\text { Past Medical } \\
\text { history }\end{array}$} & Mean BMI & 2 & 14 & 116 & 4.36 (to 0.67 to 9.38 ) & 92 \\
\hline & Obesity & 6 & $101 / 237$ & $236 / 869$ & 1.56 (1.09 to 2.13$)$ & 69 \\
\hline & Smoke/tobacco & 4 & $13 / 146$ & $20 / 683$ & $3.77(1.86$ to 7.67$)$ & 0 \\
\hline & Chronic Resp Disease (incl · asthma) & 4 & $16 / 156$ & $44 / 621$ & $1.73(0.78$ to 3.85$)$ & 32 \\
\hline & Cardiac Disease (incl·HTN) & 3 & $27 / 209$ & $36 / 695$ & $2.34(0.99$ to 5.53$)$ & 51 \\
\hline & Diabetes & 3 & $7 / 142$ & $11 / 563$ & $2.96(1.17$ to 7.47$)$ & 0 \\
\hline \multirow{2}{*}{$\begin{array}{l}\text { Pregnancy related } \\
\text { complications }\end{array}$} & GDM & 2 & $8 / 27$ & $18 / 123$ & $1.96(0.34$ to 11.34$)$ & 79 \\
\hline & Pre-eclampsia (History or existing) & 2 & $21 / 136$ & $31 / 597$ & $2.81(1.67$ to 4.75$)$ & 0 \\
\hline \multirow{5}{*}{ Management } & Antibiotic & 2 & $26 / 26$ & $109 / 122$ & 1.29 (0.63 to 2.67) & 89 \\
\hline & Antiviral & 2 & $14 / 26$ & $57 / 122$ & $1.87(1.47$ to 2.37$)$ & 0 \\
\hline & Steroids & 2 & $7 / 26$ & $33 / 122$ & $1.77(0.86$ to 3.65$)$ & 0 \\
\hline & Oxygen & 4 & $29 / 29$ & $12 / 179$ & $10.20(1.22$ to 85.09$)$ & 89 \\
\hline & ICU admission & 2 & $6 / 22$ & $5 / 92$ & $11.48(4.43$ to 29.75$)$ & 5 \\
\hline \multirow{6}{*}{$\begin{array}{l}\text { Birth and } \\
\text { neonatal } \\
\text { outcomes }\end{array}$} & Fetal loss & 2 & $0 / 137$ & $14 / 184$ & $0.17(0.02$ to 1.28$)$ & 0 \\
\hline & Vaginal births & 7 & $48 / 159$ & $262 / 539$ & $0.75(0.33$ to 1.71$)$ & 79 \\
\hline & Caesarean births & 8 & $109 / 155$ & $286 / 548$ & $1.44(0.99$ to 2.10$)$ & 79 \\
\hline & Preterm births (<37 weeks) & 5 & $63 / 219$ & $69 / 484$ & 2.41 (1.74 to 3.34$)$ & 0 \\
\hline & Mean APGAR score at $1 \mathrm{~min}$ & 1 & 7 & 63 & $-0.20(-0.72$ to 0.32$)$ & NA \\
\hline & NICU admission & 2 & $30 / 67$ & $57 / 222$ & $2.14(0.27$ to 16.98$)$ & 93 \\
\hline
\end{tabular}

BMI - body mass index, CI - confidence interval, COVID - coronavirus disease, GDM - gestational diabetes mellitus, HTN - hypertension, ICU - intensive care unit, IUGR - intrauterine growth retardation; NICU - neonatal intensive care unit, MD: mean difference, RR - risk ratio, SOB - shortness of breath 
Of all the live births, $96.9 \%$ were singleton. Less than a quarter $(23.4 \%)$ of all births were preterm ( $<37$ weeks) and very preterm (<32 weeks) (18.2\%). Almost a quarter (16.6\%) of all neonates were low birth weight (LBW) $(<2500 \mathrm{~g})$, and their mean birth weight was 2937.88g. Almost 13\% of the infants experienced asphyxia, and almost a quarter (23.7\%) of the newborn was admitted to neonatal ICU (NICU). Their mean Apgar score at 1 minute was 8.18 and at 5 minutes was 9.01. A total of 24 newborns died (1.6\%) and 21 were stillborn (1.6\%). The risk of preterm births ( $<37$ weeks) $(\mathrm{RR}=4.91 ; 95 \% \mathrm{CI}=3.97$ to 60.8$)$, very preterm birth ( $<32$ weeks) $(\mathrm{RR}=8.47 ; 95 \% \mathrm{CI}=4.02$ to 17.85$)$, and $\mathrm{NICU}$ admission ( $\mathrm{RR}=2.01 ; 95 \% \mathrm{CI}=1.50$ to 2.69 ) was higher among mothers with severe COVID-19. Similarly, mean birthweight (MD -802.79; 95\% CI $=-826.91$ to -778.67 ) was lower in severe COVID-19 cases. Of the total births, 43 newborns were COVID-19 positive (3.5\%), and six of these newborn's SARS-CoV-2 positivity was reported after 12 hours of birth [49].

\section{Comparative dichotomous studies based on the severity}

Table 5 and Figure 4 presents the pooled findings from studies that compared non-severe and severe COVID-19 cases from within the same cohort. The comparative pooled analyses showed that women with severe COVID-19 were on average 3.7 years older than women with non-severe COVID-19. Similarly, the risk of having severe COVID-19 among women older than 35 years was 1.49 times higher.

The risk of severe COVID-19 was not different based on race/ethnicity and parity. However, the risk of severe COVID-19 was higher among those who presented with fever, cough, headache, dyspnoea, and diarrhea. The risk was also higher among those who were obese, had smoked, diabetes, and pre-eclampsia.

Besides the higher proportion of women with severe COVID-19 requiring oxygen and ICU admission, the risk of preterm birth was 2.41 times higher among women with severe COVID-19.
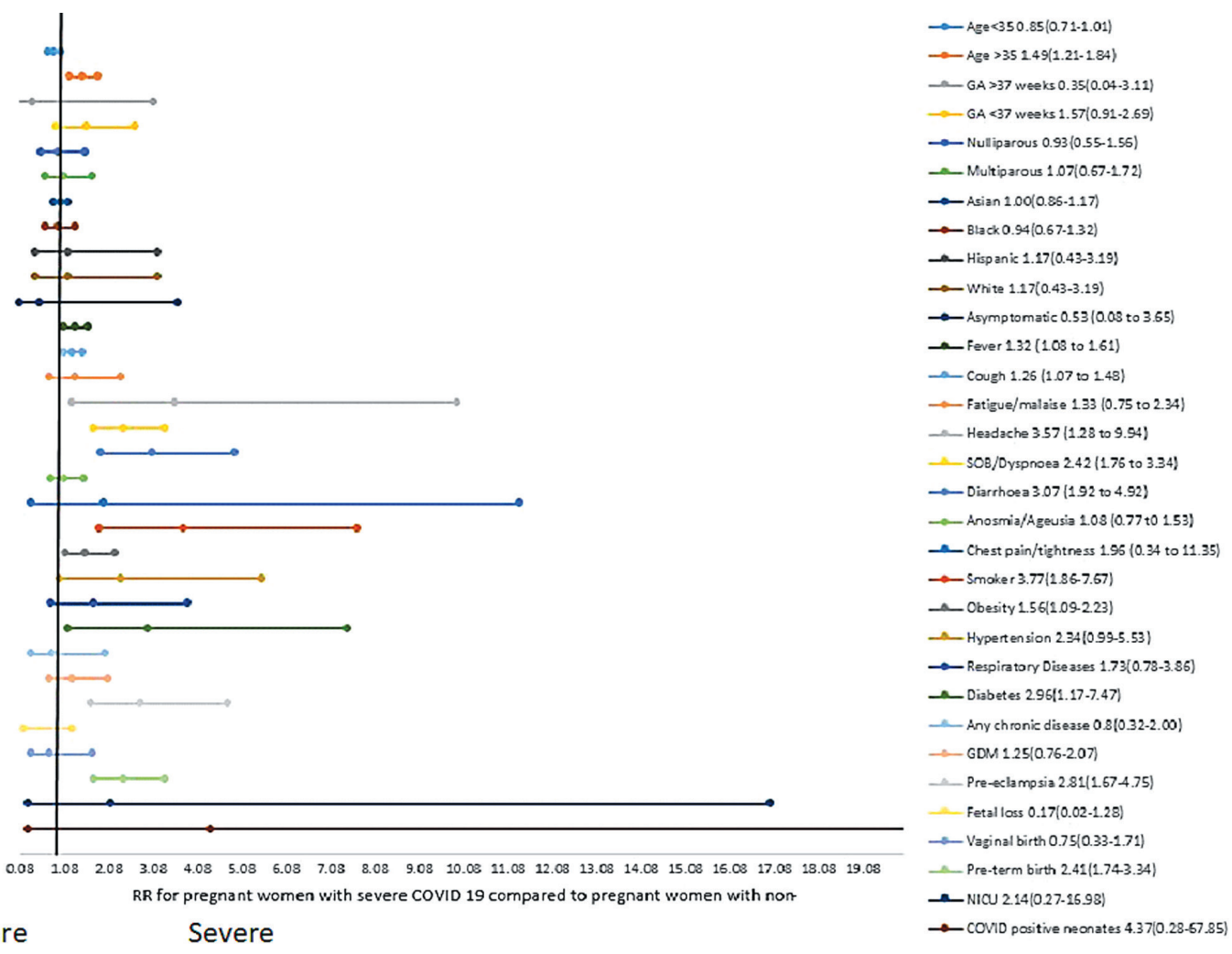

Non-severe

Severe

$\rightarrow$ COVID positive neonates $4.37(0.28-57.85$

Figure 4. Clinical presentation, risk factors, and pregnancy and perinatal outcomes: pregnant with severe and non-severe COVID-19. The figure presents pooled proportion with $95 \%$ confidence intervals using random-effect model.

\section{DISCUSSION}

To the best of our knowledge, this is the first systematic evaluation of a large number of pregnant women $(\mathrm{n}=31016)$ from 62 studies who have been assessed for the clinical presentation, risk factors, and pregnancy and perinatal outcomes based on COVID-19 severity. The review included cases from both referral and com- 
munity hospitals from 44 countries in Africa, Asia, Australia, Europe, North America, and South America. Of all included pregnant women, $78 \%$ presented to hospital during the third trimester; and severity of COVID-19 was presented in only $9 \%$ of the studies. Of those, $14 \%$ of pregnant women had severe COVID-19.

Results showed that pregnant women with severe COVID-19 were approximately 3.7 years older and the risk of severe COVID-19 was higher among women in a higher age bracket ( $>35$ years). The risk of severe COVID-19 was also higher among women who were obese, had smoked, diabetes, and pre-eclampsia. Chronic hypertension, pre-eclampsia, diabetes, and GDM have been associated with severe COVID-19 in earlier review [9]; while co-morbidities have been identified as an explanatory variable for maternal admission to ICU [14]. While almost half of all women were asymptomatic, fever, cough, fatigue, and anosmia/ageusia were the most commonly reported symptoms. Similar findings have been reported in other reviews [9-11,14]. Around half of all women were given antibiotics, anticoagulants, and hydroxychloroquine, one in three were given antivirals, and nearly one in five were managed with corticosteroids. Of all included pregnancies complicated with COVID-19 infection, 7\% were admitted to ICU, 8\% required mechanical ventilation, 15\% non-invasive ventilation, and 0.3\% ECMO. Almost half of all births occurred via cesarean section; one-quarter all births were preterm, less than one-fifth had LBW, and a quarter was admitted to NICU. However, it was not always reported in the studies if babies in need of intensive care were admitted to NICU or for isolation purposes and therefore the results could be misleading. Earlier systematic compilation of published evidence also reported similar findings $[14,57,58]$. Our review found lower rates of maternal $(2.0 \%)$ and neonatal $(1.6 \%)$ mortality and the findings are consistent with earlier reviews in the domain $[9,14,57,58]$. Neonatal SARS-CoV-2 positivity was small (3.5\%) and consistent across other evidence synthesis $[57,58]$.

Although it is a comprehensive assessment of all COVID-19 infected pregnant women, the review itself and the studies included in the review have several limitations. The findings of this review should be cautiously interpreted mainly because: first, the review included case series that brings an inherent bias due to study design, however, on quality assessment majority of these studies were rated high. Second, the majority of women (87.1\%) included in the review presented to hospitals during the third trimester, therefore we could not compare the clinical presentation in early vs late pregnancy. Third, approximately one-third of all women were asymptomatic which may be because of studies on reported universal screening for SARS-CoV-2 in women admitted for delivery. The inclusion of asymptomatic women from the universal screening may have also influenced better maternal and perinatal outcomes. Fourth, the majority of the socio-demographic and baseline health measures were not uniformly and consistently reported in all included studies; and therefore, some of the risks are very high with wider CIs because of the smaller sample size for some of the outcomes. Similarly, not all studies categorized and reported separate outcome for women infected with severe and non-severe COVID-19; therefore, results based on severity was generated from a sub-group of women included. Fifth, the indication for cesarean section was not clearly stated and it is quite possible that the decision was influenced by the anxieties and perplexities around the potential consequences of the novel coronavirus. In near future, studies around the implications of COVID-19 in pregnancy may contain thorough and complete information about both maternal and fetal conditions at the time of delivery and the rationale behind obstetrical interventions. Sixth, the review identified fewer cases from the African regions. Seventh, most of the included studies reported on advance maternal age and obesity, therefore it was easy to look at their association with COVID-19 severity. However, as more studies from low-income settings are published, it would be interesting to learn the association of underage ( $<25$ years) and underweight $(\mathrm{BMI}<18.5)$ pregnant women and the presentation of COVID-19 and its severity. Eighth, although we tried our best not to include the same case twice, there is a possibility that the case is reported more than once. Ninth, we couldn't carry out multivariable analysis to identify factors associated with severe COVID-19 among pregnant women after adjusting for socio-demographic and health profile of the women. However, in the future, if data are presented at the patient level then individual patient data meta-analysis (IPD-MA) would be an ideal approach to providing insights into recognizing and managing high-risk pregnant women. Lastly, the overall findings from this review should be interpreted with caution and the data should be constantly updated as the global COVID-19 scenario unfolds.

The results of the review indicate that the risk of severe COVID-19 is higher among pregnant women with risk factors and pre-existing co-morbidities, and the risk of poor pregnancy and perinatal outcomes of those women with severe COVID-19 are also higher. This is an area of concern as the COVID-19 pandemic is spreading around the world and most likely many pregnant women will be affected [59]. It is, therefore, important to identify high-risk women and routinely check all women coming for prenatal visits for COVID-19. In this pandemic, it is also very vital to systematize screening for all pregnant women visiting inpatient or outpatient facilities; and manage all suspected/confirmed COVID-19 cases and prepare maternity wards in the best possible way. Although our results indicate that the risk of vertical transmission is very low, it is important to in- 
stitute appropriate protective measures and hygiene procedures during delivery. Mothers should be advised to wear a medical mask during any contact with the baby such as during breastfeeding, skin-to-skin care, and should be supported to share a room with the baby. Management of pregnant women and babies infected with COVID-19 should be performed following national or international guidelines.

\section{CONCLUSIONS}

This review provides information required to guide current care during this pandemic and health care providers may consider these findings for effective management of pregnant women infected with COVID-19 that would reduce pregnancy-related adverse consequences including maternal and newborn morbidity and mortality. At the same time, it is important to interpret the findings cautiously and update them constantly as the pandemic unfolds. Studies from Denmark and Ireland have reported falling numbers in premature and very and extremely LBW babies particularly those born before 28 weeks in many parts of the world by startling 70 to 90 percent $[60,61]$, our review only depended upon reported case-series and smaller population data that did not report on falling numbers of preterm births in the population. While, these findings are counterintuitive and researchers have speculated an association with strict lockdown and isolation; whereby women may have experienced less stress from work and commute, more support from families at home, and less exposure to air pollution and infections in general (such as influenza). Although the finding pertains to a general reduction in the overall rates of premature births and not necessarily implies to women infected with COVID-19, but such elusive observations are providing directions for future research. More coalitions are built for better prospective data collection and international surveillance and a few of these efforts include the WHO Collaborative and International Perinatal Outcomes in the Pandemic (iPOP).

Funding: No funding source.

Authorship contribution: ZSL initially conceptualized the paper with JKD, RAS, and ZAB; ZSL and AA did the statistical analysis; ZSL and AA did the data extraction, ZAP and ZSL did the quality assessment; ZSL wrote the first draft of the paper with inputs from all the authors.

Competing interests: The authors completed the ICMJE Unified Competing Interest form (available upon request from the corresponding author), and declare no conflicts of interest.

Additional material

Online Supplementary Document

1 COVID-19 Dashboard by the Center for Systems Science and Engineering (CSSE) at John Hopkins University. Available: https:// www.arcgis.com/apps/opsdashboard/index.html\#/bda7594740fd40299423467b48e9ecf6. Accessed: 2 June 2020.

2 WHO. Naming the coronavirus disease (COVID-2019) and the virus that causes it. Available from: https://www.who.int/emergencies/diseases/novel-coronavirus-2019/technicalguidance/naming-the-coronavirus-disease-(covid-2019)-and-the-virus-thatcauses-it (accessed 20 April 2020). World Health Organization.

3 Dorn AV, Cooney RE, Sabin ML. COVID-19 exacerbating inequalities in the US. Lancet. 2020;395:1243-4. Medline:32305087 doi:10.1016/S0140-6736(20)30893-X

4 Rodriguez-Morales AJ, Cardona-Ospina JA, Gutiérrez-Ocampo E, Villamizar-Pena R, Holguin-Rivera Y, Escalera-Antezana JP, et al. Clinical, laboratory and imaging features of COVID-19: A systematic review and meta-analysis. Travel Med Infect Dis. 2020;34:101623. Medline:32179124 doi:10.1016/j.tmaid.2020.101623

5 Liu H, Wang L-L, Zhao S-J, Kwak-Kim J, Mor G, Liao A-H. Why are pregnant women susceptible to viral infection: an immunological viewpoint? J Reprod Immunol. 2020;139:103122. Medline:32244166 doi:10.1016/j.jri.2020.103122

6 Lam CM, Wong SF, Leung TN, Chow KM, Yu WC, Wong TY, et al. A case-controlled study comparing clinical course and outcomes of pregnant and non-pregnant women with severe acute respiratory syndrome. BJOG. 2004;111:771-4. Medline:15270922 doi:10.1111/j.1471-0528.2004.00199.x

7 Wong SF, Chow KM, Leung TN, Ng WF, Ng TK, Shek CC, et al. Pregnancy and perinatal outcomes of women with severe acute respiratory syndrome. Am J Obstet Gynecol. 2004;191:292-7. Medline:15295381 doi:10.1016/j.ajog.2003.11.019

8 Di Mascio D, Khalil A, Saccone G, Rizzo G, Buca D, Liberati A, et al. Outcome of coronavirus spectrum infections (SARS, MERS, COVID-19) during pregnancy: a systematuc review and meta-analysis. Am J Obstet Gynecol MFM. 2020;2:100107. Medline:32292902 doi:10.1016/j.ajogmf.2020.100107

9 Allotey J, Stalling E, Bonet M, Yap M, Chatterjee S, Kew T, et al. Clinical manifestations, risk factors, and maternal and perinatal outcomes of coronavirus disease 2019 in pregnancy: living systematic review and meta-analysis. BMJ. 2020;370:m3320. Medline:32873575 doi:10.1136/bmj.m3320 
10 Ali Khan MMA, Khan MN, Mustagir MG, Rana J, Haque MR, Rahman MM. COVID-19 infection during pregnancy: a systematic review to summarize possible symptoms, treatments, and pregnancy outcomes. MedRxiv. 2020. doi:10.1101/2020.06.0 $3.20121442 \mathrm{vl}$.

11 Arabi S, Vaseghi G, Heidari Z, Shaiati L, Amin B, Rashid H, et al. Clinical characteristics of COVID-19 infection in pregnant women: a systematic review and meta-analysis. MedRxiv. 2020. doi:10.1101/2020.04.05.20053983

12 Della Gatta AN, Rizzo R, Pilu G, Simonazzi G. COVID19 during pregnancy: a systematic review of reported cases. Am J Obstet Gynecol. 2020;223:36-41. Medline:32311350 doi:10.1016/j.ajog.2020.04.013

13 Kasraeian M, Zare M, Vefaei H, Asadi N, Faraji A, Bazrafshan K, et al. COVID-19 pnuemonia and pregnancy; a systematic review and meta-analysis. J Mater Fetal Neonat Med. 2020. Online ahead of print. doi:10.1080/14767058.2020.1763952

14 Khalil A, Kalafat E, Benlioglu C, O’Brien P, Morris E, Draycott T, et al. SARS-CoV-2 infection in pregnancy: a systematic review and meta-analysis of clinical features and pregnancy outcomes. EClinicalMedicine. 2020;25:100446. Medline:32838230 doi:10.1016/j.eclinm.2020.100446

15 Moher D, Liberati A, Tetzlaff J, Altman DG. Preferred reporting items for systematic reviews and meta-analyses: the PRISMA statement. PLoS Med. 2009;6:e1000097. Medline:19621072 doi:10.1371/journal.pmed.1000097

16 WHO. Global surveillance for COVID-19 caused by human infection with COVID-19 virus: interim guidance. Geneva World Health Organization; 2020.

17 COVIDENCE. Covidence systematic review software, Available at www.covidence.org. Melbourne, Australia.: Veritas Health Innovation; 2020

18 NHLBI. Quality assessment tool for observational cohort and cross-sectional studies. [https://www. nhlbi. nih. gov/health-topics/study-quality-assessment-tools]. National Heart, Lung, and Blood Institute. 2019.

19 Borenstein M, Hedges L, Higgins J. H. R. Comprehensive Meta-Analysis Version 3. Englewood, NJ: Biostat; 2013.

20 SUMARI. System for the Unified Management of the Assessment and Review of Information (SUMARI). J Med Libr Assoc. 2019;107:634-6.

21 Altman DG. Practical statistics for medical research. London: Chapman and Hall; 1991.

22 WHO. Clinical management of COVID-19: Interim guidance Geneva World Health Organization 2020.

232019 RW. Review MAnager Web (RevMan Web). The Cochrane Collaboration; 2019.

24 Zhang L, Jiang Y, Wei M, Cheng BH, Zhou XC, Li J, et al. Analysis of the pregnancy outcomes in pregnant women with COVID-19 in Hubei Province. Zhonghua Fu Chan Ke Za Zhi. 2020;55:166-71. Medline:32145714

25 Juusela A, Nazir M, Gimovsky M. Two cases of COVID-19 related cardiomyopathy in pregnancy. Am J Obstet Gynecol MFM. 2020;2:100113. Medline:32363336 doi:10.1016/j.ajogmf.2020.100113

26 Lokken EM, Walker CL, Delaney S, Kachikis A, Kretzer NM, Erickson A, et al. Clinical Characteristics of 46 Pregnant Women with a SARS-CoV-2 Infection in Washington State. Am J Obstet Gynecol. 2020;223:911.e1-911.e14. Medline:32439389 doi:10.1016/j.ajog.2020.05.031

27 Yan J, Guo J, Fan C, Juan J, Yu X, Li J, et al. Coronavirus disease 2019 (COVID-19) in pregnant women: A report based on 116 cases. Am J Obstet Gynecol. 2020;223:111.el-111.e14. Medline:32335053 doi:10.1016/j.ajog.2020.04.014

28 Cohen J, Vignaux O, Jacquemard F. Covid-19 in pregnant women: General data from a French National Survey. Eur J Obstet Gynecol Reprod Biol. 2020;251:267-8. Medline:32540156 doi:10.1016/j.ejogrb.2020.06.002

29 Zheng T, Guo J, He W, Wang H, Yu H, Ye H. Coronavirus disease 2019 (COVID-19) in pregnancy: 2 case reports on maternal and neonatal outcomes in Yichang city, Hubei Province, China. Medicine (Baltimore). 2020;99:e21334. Medline:32702930 doi:10.1097/MD.0000000000021334

30 Qiancheng X, Jian S, Lingling P, Lei H, Xiaogan J, Weihua L, et al. Coronavirus disease 2019 in pregnancy. Int J Infect Dis. 2020;95:376-83. Medline:32353549 doi:10.1016/j.ijid.2020.04.065

31 Liu Y, Chen H, Tang K, Guo Y. Clinical manifestations and outcome of SARS-CoV-2 infection during pregnancy. J Infect. 2020. Online ahead of print. Medline:32145216 doi:10.1016/j.jinf.2020.02.028

32 Huang W, Zhao Z, He Z, Liu S, Wu Q, Zhang X, et al. Unfavorable outcomes in pregnant patients with COVID-19. J Infect. 2020;81:e99-101. Medline:32417313 doi:10.1016/j.jinf.2020.05.014

33 Kayem G, Alessandrini V, Azria E, Blanc J, Bohec C, Bornes M, et al. A snapshot of the Covid-19 pandemic among pregnant women in France. J Gynecol Obstet Hum Reprod. 2020;49:101826. Medline:32505805 doi:10.1016/j.jogoh.2020.101826

34 Martínez-Perez O, Vouga M, Cruz Melguizo S, Acebal LF, Panchaud A, Chápuli M, et al. Association Between Mode of Delivery Among PregnantWomenWith COVID-19 and Maternal and Neonatal Outcomes in Spain. JAMA. 2020;324:296-9. Medline:32511673 doi:10.1001/jama.2020.10125

35 Khoury R, Berstein PS, Debolt C, Stone J, Sutton DM, Simpson LL, et al. Characteristics and Outcomes of 241 Births to Women With Severe Acute Respiratory Syndrome Coronavirus 2 (SARS-CoV-2) Infection at Five New York City Medical Centers. Obstet Gynecol. 2020;136:273-82. Medline:32555034 doi:10.1097/AOG.0000000000004025

36 Chen L, Li Q, Zheng D, Jiang H, Wei Y, Zou L, et al. Clinical characteristic of pregnant women with covid-19 in Wuhan, China. N Engl J Med. 2020;382:e100. Medline:32302077 doi:10.1056/NEJMc2009226

37 Mendoza M, Garcia-Ruiz I, Maiz N, Rodo C, Garcia-Manau P, Serrano B, et al. Preeclampsia like syndrome induced by severe COVID-19: a prospective observational study. BJOG. 2020;127:1374-80. Medline:32479682 doi:10.1111/1471-0528.16339

38 San-Juan R, Barbero P, Fernandex-Ruiz M, Lopez-Medrano F, Lizasoain M, Hernandez-Jimenez P, et al. Incidence and clinical profiles of COVID-19 pneumonia in pregnant womne: a single-centre cohort study from Spain. EClinicalMedicine. 2020;23:100407. Medline:32632417 doi:10.1016/j.eclinm.2020.100407

39 Mohr-Sasson A, Chayo J, Bart Y, Meyer R, Sivan E, Mazaki-Tovi S, et al. Laboratory characteristics of pregnant compared to non-pregnant women infected with SARS-CoV-2. Arch Gynecol Obstet. . Medline:32572616 doi:10.1007/s00404-020-05655-7 
40 Dória M, Perixinho C, Laranjo M, Verejao AM, Silva PT. Covid-19 during pregnancy: A case series from an universally tested population from the north of Portugal. Eur J Obstet Gynecol Reprod Biol. 2020;250:261-2. Medline:32425298 doi:10.1016/j. ejogrb.2020.05.029

41 London V, McLaren R, Atallah F, Cepeda C, McCalla S, Fisher N, et al. The Relationship between Status at Presentation and Outcomes among Pregnant Women with COVID-19. Am J Perinatol. 2020;37:991-4. Medline:32428964 doi:10.1055/s-0040-1712164

42 Duffy CR, Hart JM, Modest AM, Hacker MR, Golen T, Li Y, et al. Lymphopenia and severe acute respiratory syndrome coronavirus 2 (SARS-CoV-2) infection among hospitalized obstetric patients. Obstet Gynecol. 2020;136:229-31. Medline:32433451 doi:10.1097/AOG.0000000000003984

43 Savasi VM, Parisi F, Patane L, Ferrazzi E, Frigerio L, A. P, et al. Clinical findings and disease severity iin hospitalised pregnant women with coronavirus disease 2019 (Covid-19). Obstet Gynecol. 2020;136:252-8. Medline:32433453 doi:10.1097/ AOG.0000000000003979

44 Goldfarb IT, Clapp MA, Soffer MD, Shook LL, Rushfirth K, Edlow AG, et al. Prevalence and Severity of Coronavirus Disease 2019 (COVID-19) Illness in Symptomatic Pregnant and Postpartum Women Stratified by Hispanic Ethnicity. Obstet Gynecol. 2020;136:300-2. Medline:32496337 doi:10.1097/AOG.0000000000004005

45 Nayak AH, Kapote DS, Fonesca M, Chavan N, Mayekar R, Sarmalkar M, et al. Impact of the coronavirus infection in pregnancy: a preliminary study of 141 pateints. J Obstet Gynaecol India. 2020;70:256-61. Medline:32760169 doi:10.1007/s13224020-01335-3

46 Pierce-Williams RAM, Burd J, Felder L, Khouray R, Bernstein PS, Avila K, et al. Clinical course of severe and critical COVID-19 in hospitalized pregnancies: a US cohort study. Am J Obstet Gynecol MFM. 2020;2:100134. Medline:32391519 doi:10.1016/j. ajogmf.2020.100134

47 McLaren RA, London V, Ataullah F, McCalla S, Haberman S, Fisher N, et al. Delivery For Respiratory Compromise Among Pregnant Women With COVID-19. Am J Obstet Gynecol. 2020;223:451-3. Medline:32454031 doi:10.1016/j.ajog.2020.05.035

48 Qadri F, Mariona F. PRegnancy affected by SARS-CoV-2 infection: a flash report from Michigin. J Matern Fetal Neonatal Med. 2020. Online ahead of print. Medline:32434403 doi:10.1080/14767058.2020.1765334

49 Knight M, Bunch K, Vousden N, Morris E, Simpson N, Gale C, et al. Characteristics and outcomes of pregnant women admitted to hospital with confirmed SARS-CoV-2 infection in UK: national population based cohort study. BMJ. 2020;369:m2107. Medline:32513659 doi:10.1136/bmj.m2107

50 Sahin D, Tanacan A, Erol SA, Anuk AT, Yetiskin FDY, Keskin HL. Updated experience of a tertiary pandemic center on 533 pregnant women with COVID-19 infection: A prospective cohort study from Turkey. Int J Gynaecol Obstet. 2021;152:32834. Medline:33131057 doi:10.1002/ijgo.13460

51 Nie R, Wang S, Yang Q, Fan C, Liu Y, He W, et al. Clinical features and the maternal and neonatal outcomes of pregnant women with coronavirus disease 2019. MedRxiv. 2020. doi:10.1101/2020.03.22.20041061

52 Griffin I, Benarba F, Peters C, Oyelese Y, Murphy T, Contreras D, et al. The impact of COVID-19 infection on labor and delivery, newborn nursey, and neonatal intesive care unit: propective observational datafrom a single hospital system. Am J Perinatol. 2020;37:1022-30. Medline:32534458 doi:10.1055/s-0040-1713416

53 Khan MA, Kumar V. SR A. Vertical Transmission of Novel Coronavirus (COVID-19) from Mother to Newborn: Experience from a Maternity Unit, The Indus Hospital, Karachi. J Coll Phy Surg Pak. 2020;30:S136.

54 Mercedes BR, Serwat A, Naffaa L, Ramirez N, Khalid F, Steward SB, et al. New-onset myocardial injury in pregnant patients with coronavirus disease 2019: a case series of 15 patients. Am J Obstet Gynecol. 2021;224:387.e1-387.e9. Medline:33098814 doi:10.1016/j.ajog.2020.10.031

55 Sattari M, Bashirian S, Masoumi SZ, Shayan A, Jenabi E, Ghelichkhani S, et al. Evaluating Clinical Course and Risk Factors of Infection and Demographic Characteristics of Pregnant Women with COVID-19 in Hamadan Province, West of Iran. J Res Health Sci. 2020;20:e00488. Medline:33169720 doi:10.34172/jrhs.2020.22

56 Shmakov RG, Prikhodko A, Polushkina E, Shmakova E, Pyregov A, Bychenko V, et al. Clinical course of novel COVID-19 infection in pregnant women. J Matern Fetal Neonatal Med. 2020. Online ahead of print. Medline:33249969 doi:10.1080/147 67058.2020 .1850683

57 Ferrazzi E, Frigerio L, Savasi V, Vergani P, Prefumo F, Barresi S, et al. Vaginal delivery in SARS-CoV-2 infected pregnant women in northern Italy: a retrospective analysis. BJOG. 2020;127:1116-21. . Published online April 27, 2020. Medline:32339382 doi:10.1111/1471-0528.16278

58 Ashraf MA, Keshavarz P, Hosseinpour P, Erfani A, Roshanshad A, Pourdast A, et al. Coronavirus disease 2019 (COVID-19): a systematic review of pregnancy and the possibility of vertical transmission. J Reprod Infertil. 2020;21:157-68. Medline:32685412

59 Schuchat A. Reflections on pandemics, past and present. Am J Obstet Gynecol. 2011;204(Suppl 1):S4-6. Medline:21419383 doi:10.1016/j.ajog.2011.02.039

60 Hedermann G, Gedley PL, Baekvad-Hansen M, Hjalgrim H, Rostgaard K, Poorisrisak P, et al. Danish premature birth rates during the COVID-19 lockdown. Arch Dis Child Fetal Neonatal Ed. 2021;106:93-5. Medline:32788391 doi:10.1136/archdischild-2020-319990

61 Philip RK, Purtill H, Reidy E, Daly M, Imcha M, McGrath D, et al. Reduction in preterm births during the COVID-19 lockdown in Ireland: a natural experiment allowing analysis of data from the prior two decades. MedRxiv. 2020. doi:10.1016/j. ejogrb.2020.05.029 